\title{
Pseudomyxomaperitonei: A Rare Clinical Entity - A Case Report
}

\author{
Hossain $\mathrm{MF}^{1}$, Hossain $\mathrm{MD}^{2}$, Begum $\mathrm{M}^{3}$, Shamsi $\mathrm{AMO}^{4}$
}

\begin{abstract}
Pseudomyxomaperitonei (PMP) is a rare disease characterized by presence of gelatinous ascites and mucinous implants on the peritoneum and omentum. We report the case of a 58 years old woman with primary tumour of the appendix and secondary involvement of other structures \& organs of abdominal cavity. Aim of this case report is to create awareness among the clinicians regarding this uncommon disease presented with ascites and irregular masses in the abdomen. In addition, literature on the clinical presentation, diagnostic procedures, and treatment options has been briefly reviewed.
\end{abstract}

\section{Keywords}

Pseudomyxomaperitonei, Mucinous carcinomatosis, Hyperthermic intraperitoneal chemotherapy, Gelatinous material.

\section{Introduction}

Pseudomyxomaperitonei (PMP) is an uncommon condition characteristically arise from ruptured, primary appendiceal or ovarian adenomas or adenocarcinomas, but can have an indeterminate site. ${ }^{1,2}$ PMP was 1 st described by Rokitansky in $1842 .{ }^{3}$ Incidence is one per million per year ${ }^{4}$ and encountered in 2 of 10,000 laparotomies with gelatinous masses called "Jelly belly".5,6 It is three to four times more in women than in men. ${ }^{7}$ The median age of presentation is 54 years. $^{8}$ Tumour often arises from goblet cells of large bowel or appendix. Despite the abdominal viscera being thickly coated with the mucus-secreting tumour cells, invasion into the substance or extraperitoneal sites does not occur. Instead, the abdominopelvic cavities become filled with tenacious, semisolid, neoplastic mucus, rich in glycoproteins. This paper highlights the diagnosis \& management of pseudomyxomaperitonei of a patient presented with clinical features of ascites and irregular masses in the abdomen.

\section{Case report}

A 54 years old diabetic female, previously diagnosed as a case of mucinous adenocarcinoma of ovary (Stage-IIIc), came to oncology OPD of Apollo Hospitals Dhaka in March 2017 with the complaints of lower abdominal discomfort for 15 days. She had already received 2 cycles of chemotherapy. Earlier (5 months back) as a part of diagnostic workup she underwent laparotomy in a private hospital, Dhaka. Only biopsy was taken from suspected tissue at that time. She was found to be severely anemic so was admitted for blood transfusion and further evaluation. Her

1. Consultant, Dept. of General, Laparoscopy \& G.I. Surgical Oncology,Apollo Hospitals Dhaka 2. Senior registrar, Dept. of General \& Laparoscopic Surgery, Apollo Hospitals Dhaka 3. Sr. Consultant, Dept. of Gynaecology \& Obstetrics, Apollo Hospitals Dhaka 4. Resident Medical Officer, Dept. of General \& Laparoscopic Surgery, Apollo Hospitals Dhaka 
transfusion and further evaluation. Her abdomen was soft, non-tender but hugely distended mostly in the lower part and an ill-defined intraabdominal lump was palpable in the lower abdomen. Examination of other system revealed no significant abnormality. Except low Hb level other lab parameters were within normal limit. Chest X-ray showed left pleural effusion. CT scan of whole abdomen with $\mathrm{i} / \mathrm{v} \&$ rectal contrast revealed a large conglomerated mass completely encasing the uterus \& occupying pelvis displacing other pelvic organ. There is marked omental thickening and extensive spread of low attenuation masses in the abdomen and pelvis encasing the bowel loops, causing scalloping of liver margins. Ovaries and appendix weren't sepa-

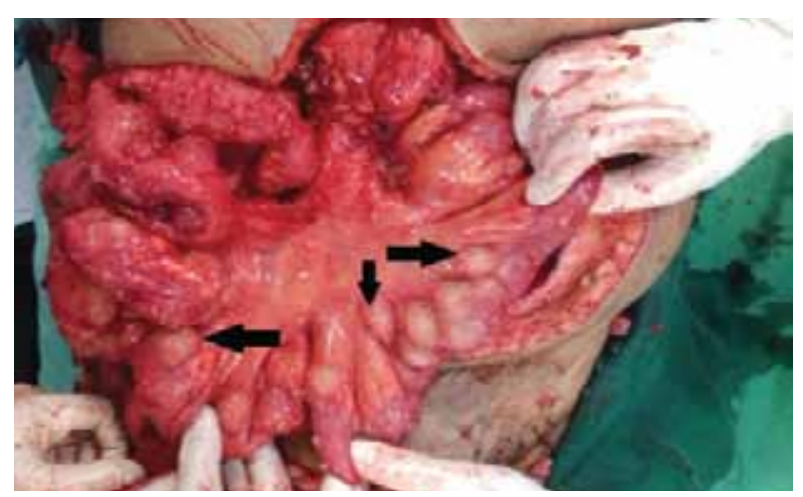

Fig. 1: Extensive myxomatous deposits (Arrow marks) in small bowel mesentery.

separately identifiable. Minimal free fluid was seen in abdomen and pelvis. All these features were consistent with pseudomyxomaperitonei. The case was discussed in tumour board and decided to go for tumour debulking surgery followed by adjuvant chemotherapy. Per operatively there was extensive myxomatous deposit deposit all over the parietal peritoneum, liver surface, small \& large bowel wall \& mesentery (Fig. 1), greater curvature of stomach, pelvis, calot's triangle and omentum forming cake.

Both ovaries were extensively enlarged with myxomatous mass. There was a large firm appendicular mass $(8 \times 6) \mathrm{cm}$ at the ileocecal junction (Fig. 2).

Uterus was found normal. Total abdominal hysterectomy with bilateral salpingo- oophorectomy followed by right hemicolectomy with cholecystectomy, omentectomy and excision of most of the peritoneal deposits were done (Fig. 3).

Due to technical problem hyperthermic intraperitoneal chemotherapy (HIPEC) couldn't be

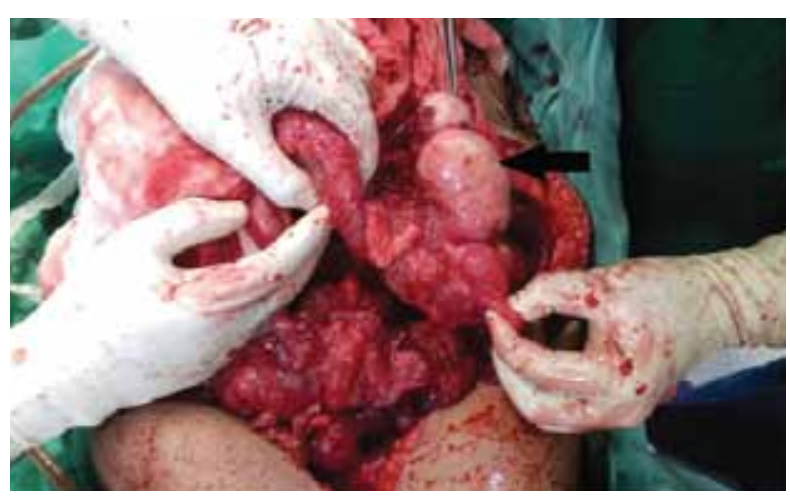

Fig. 2: Appendicular mass (Arrow mark) at the ileo-caecal junction.

be administered. All the specimen was sent for histopathology which revealed features consistent with mucinous cystadenocarcinoma of appendix with high grade pseudomyxomaperitonei involving omentum, outer surface of both small and large gut and outer wall of uterus and ovaries. Postoperative 
recovery was satisfactory and the patient was discharged 10 days after surgery with follow up advice to oncology OPD for adjuvant chemotherapy. On subsequent visit at surgery OPD no major complication detected and the patient is still alive without any significant complaints even 1 year after operation.

\section{Discussion}

Mucinous lesions can be found in different locations in the body, but the most common are bowel (appendix) and ovarian tumors. ${ }^{10,11}$ These lesions can be seen in benign, intermediate and malignant variants, but the most serious complication is clinically called peritoneal pseudomyxoma. It is an indolent disease and is most prevalent in women aged between 50 and $70 .{ }^{12}$ In our case, primary site of origin is appendix with secondary involvement in both ovaries, omentum and peritoneum, while implants were also found in appendice epiploicae.

Clinically, although painless, deterioration of general health begins long before diagnosis. The main complaints are those of abdominal pain and distension. Surprisingly, signs and symptoms of cancer such as cachexia are rare. Preoperative diagnosis could therefore be made with careful physical examination in conjunction with ultrasound and computed tomography. Ultrasonography is useful and generally has similar features to computed tomography images showing abdominal echogenic masses with ascites, multiple septations, and scalloping of the

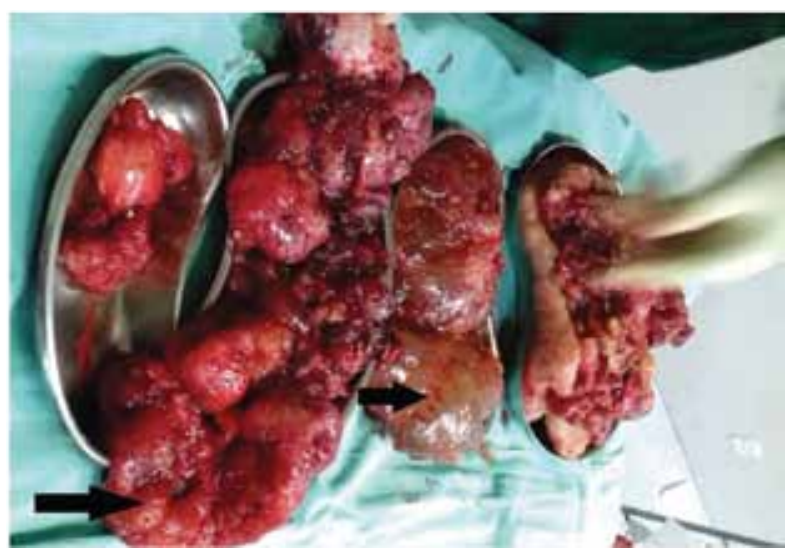

Fig. 3: Gelatinous deposits (arrow marks) excised from peritoneal cavity.

liver. ${ }^{13-16}$ Computed tomography shows four basic patterns: (1) posterior displacement of the intestines with numerous low density masses and calcifications; (2) diffuse peritoneal infiltration appearing similar to ascites with septated fluid pockets filling the peritoneal cavity; (3) intrahepatic low density attenuated lesions ${ }^{13}$; and (4) scalloping of intra-abdominal organs due to extrinsic pressure of adjacent peritoneal implants. Scalloping of the liver has been widely described. However, explorative laparotomy still remains the main diagnostic tool of choice. A positive finding is indicated by the presence of litres of yellowish-grey mucoid material involving both the omental and peritoneal surfaces. ${ }^{17,18}$ Prompt and aggressive treatment, including drainage of the mucus, surgical debulking of the primary and secondary tumour implants, and resection of the omentum should be instituted in all patients. Commonly, at laparotomy a right hemicolectomy is performed. In order to prevent recurrence, resection of both ovaries and the appendix must be carried out in all female 
appendix must be carried out in all female patients where the primary site is not found. Unfortunately, recurrences are usual but less frequent when appendiceal mucoceles give rise to pseudomyxomaperitonei. Additional intraperitoneal chemotherapy is also reasonably effective, particularly for ovarian carcinomas. ${ }^{21}$ 5-Fluorouracil is especially recommended for this purpose. After completing parenteral chemotherapy and a control CT examination, second-look surgery should have been performed with the aim of reducing any eventual residual tumor tissue on the diaphragm domes and liver, as part of a protocol in such cases. ${ }^{19,20}$ In 1996, Sugarbaker et al stated in their paper that clinical features, which correlate significantly with therapy failure, are tumour site, histopathological grade, preoperative cancer volume, and completeness of cancer removal by cytoreductive surgery. Therefore, improvements in surgical technologies to increase total clearance of tumor from the abdominal cavity and chemotherapy are required to sustain control of small volume residual disease on all peritoneal surfaces. ${ }^{21}$

Approximately two thirds of patients eventually succumb to local or regional disease, but the slow progression of metastatic disease and the advent of modern therapeutic regimens have led to prolonged survival in pseudomyxomaperitonei. Generally, five and 10-year survival rates are thought to be around $50 \%$ and $20 \%$ respectively. Peritonectomy, omentectomy, and combination intraperitoneal chemotherapy with mitomycin $\mathrm{C}$ and 5-fluorouracil has been reported to achieve 10 -year survival rates of up to $80 \%{ }^{22}$

\section{Conclusion}

Pseudomyxomaperitonei is a relatively rare and poorly understood condition. We have described a case in which pseudomyxomaperitonei developed as a result of appendiceal tumours. Awareness of this rare condition allows appropriate primary debulking surgery to be performed when faced with a "belly full of jelly". Although there are advantages and disadvantages of available investigation techniques and treatment regimens but their use continues to be invaluable in patients with pseudomyxomaperitonei.

\section{References}

1. Lang H1, Jähne J, Flemming P, Meyer HJ, Pichlmayr R. Pseudomyxomaperitonei of appendiceal origin - a report of seven cases and a review of published reports. Eur J Surg. 1995;161(5): 355-60.

2.Limber GK, King RE, Silverberg SG. Pseudo- myxomaperitonei. Ann Surg. 1973; 178:587-93.

3. Carter J, Moradi MM, Eig S. Pseudomyxomaperitonei -experience from a tertiary referral center. Aust NZ J obstetGynaecolPathol. 1992;31: 177-8.

4. Saleem SM, Mehboob M, Qayyum A. Pseudo- myxomaperitonei: A rare clinical entity. Journal of Surgery Pakistan. 2008; 13:139-40.

5. Sanford HB, Kathryn M. Pseudomyxomaperitonei. N Eng J med. 2004;350: 15.

6. Mann WJ, Wagner J, Chumas J, Chalas E. The management of pseudo myxomaperitonei. management of pseudo- myxomaperitonei. Cancer. 1990;66: 1636-40.

7. Hinson FL, Ambrose NS. Pseudomyxomaperitonei. Br J Surg. 1998; 85:1332-39.

8. Cough DB, Donohue JH, Schutt AJ. Pseudo- myxomaperitonei - long term patient survival with an aggressive regional approach. Ann Surg.1994; 219:112-9.

9. Fann JI, Viersa M, Fisher D. Pseudomyxomaperitonei. SurgGynecol Obstet.1993; 177:441-7.

10. Mukherjee A, Moran B. Pseudo myxomaperitoneisymptoms, signs and clinical differential diagnosis. CME J. 
10. Mukherjee A, Moran B. Pseudomyxomaperitoneisymptoms, signs and clinical differential diagnosis. CME J. Gynecol. Oncol. 2003; 8:199.

11. Smeenk RM, Verwaal VJ, Zoetmulder FA. Pseudo myxomaperitonei. Cancer Treat. Rev. 2007; 33:138.

12. Beller FK, Zimmerman RE, Nienhaus H. Biochemical identification of mucus of pseudomyxomaperitonei as the basis of mucolytic treatment. Am J Obstet Gynecol.1986; 155:970-3.

13. Lawate PS, Singh SP, Jasper MP, William R, Bharathi MV, Rolston DD. Computed tomography and sonographic features of pseudomyxomaperitonei. AJR Am J Roentgenol. 1989;152: 429.

14. Seshul MB, Coulan CM. Pseudomyxomaperitonei: computed tomography and sonography. AJR Am J Roentgenol.1981; 136:803-6.

15. Foster DR. Ultrasound Findings in Pseudo myxomaPeritonei. AustralasRadiol.1985; 29:39-41.

16. Yeh HC, Shafir MK, Slater G, Meyer RJ, Cohen BA, and
Geller SA. Ultrasonography and computed tomography in pseudomyxomaperitonei. Radiology.1984; 153(2):507-10. 17. Ronnett BM, Shmookler BM, Diener-West M, Sugarbaker PH, Kurman RJ. Immunohistochemical evidence supporting the appendiceal origin of pseudomyxomaperitonei in women. Int J GynecolPathol.1997; 16(1):1-9

18. Buy JN, Malbec L, Ghossain MA, Guinet C, Ecoiffier J. Magnetic Resonance Imaging of PseudomyxomaPeritonei. Eur J Radiol.1989; 9(2):115-8.

19. Sugarbaker PH. Disseminated appendiceal mucinous tumors and the pseudomyxomaperitoneisydrome. Gynecol. Oncol. 2003; 8: 204.

20. Esquivel J, Sugarbaker PH. Clinical presentation of the pseudomyxomaperitonei syndrome. Br. J. Surg. 2000; 87:1414.

21. Sugarbaker PH, Fernandez-Trigo V, Shamsa F. Clinical determinants of treatment failure in patients with pseudomyxomaperitonei. Cancer Treat Res.1996; 81:121-32.

22. Sugarbaker PH. Pseudomyxomaperitonei. Cancer Treat Res 1996; 81:105-19. 